\title{
A novel catalytic adsorptive stripping voltammetric method for the determination of germanium ultratraces in the presence of chloranilic acid and the V(IV).HEDTA complex
}

\author{
Jerzy Zarębski ${ }^{1}$ - Andrzej Bobrowski ${ }^{1}$ • Agnieszka Królicka ${ }^{1}$ - Julia Gonciarczyk ${ }^{1}$ • Vasiliki Manolopoulou ${ }^{2}$. \\ Anastasios Economou ${ }^{2}$
}

Received: 2 May 2020 / Revised: 22 May 2020 / Accepted: 23 May 2020 / Published online: 11 July 2020

(C) The Author(s) 2020

\begin{abstract}
A novel, sensitive catalytic adsorptive stripping voltammetric procedure which can be used to determine trace amounts of germanium is described. The method is based on the interfacial accumulation of the complex formed by Ge(IV) and the product of the reduction of chloranilic acid on the hanging mercury drop electrode or the renewable silver amalgam film electrode, and its subsequent reduction from the adsorbed state followed by the catalytic action of the V(IV)·HEDTA complex. The presence of V(IV).HEDTA greatly enhances the adsorptive stripping response of Ge. The reduction of the Ge(IV) in the presence of chloranilic acid and V(IV)-HEDTA was investigated in detail and the effects of $\mathrm{pH}$, electrolyte composition, and instrumental parameters were studied. Under optimal conditions, the catalytic peak current of germanium exhibited good linearity for Ge(IV) concentrations in the range of $0.75-60 \mathrm{nM}$ (for $60 \mathrm{~s}$ of accumulation at $\left.-0.1 \mathrm{~V}, r^{2}=0.995\right)$ and a low limit of detection (LOD = $0.085 \mathrm{nM}$ ). The procedure was successfully applied to determine Ge in water samples.
\end{abstract}

Keywords Germanium determination · Chloranilic acid · HEDTA vanadium(IV) complexes · Catalytic adsorptive stripping voltammetry $\cdot$ Silver amalgam film electrode

\section{Introduction}

Germanium was discovered by Winkler in 1885 and has been since the subject of many papers concerning its properties and those of its compounds. The studied areas included the influence of germanium compounds on living organisms and the human body, their ingestion, and the health consequences [1-3]. Although germanium may in some cases be essential

Dedicated to Professor Fritz Scholz on the occasion of his 65th birthday.

Andrzej Bobrowski

abobrow@agh.edu.pl

$\triangle$ Agnieszka Królicka

krolicka@agh.edu.pl

1 Department of Building Materials Technology, Faculty of Materials Science and Ceramics, AGH University of Science and Technology, Mickiewicza 30, 30-059 Krakow, Poland

2 Department of Chemistry, Laboratory of Analytical Chemistry, University of Athens, 15771 Athens, Greece for development, it can also adversely affect vital functions. Consequently, it is essential to monitor the content of this element in food, water, and other potential sources of ingestion as well as its concentration in tissue by applying selective and sensitive methods of its determination.

Many analytical methods have been applied to determine germanium [4-6]; electrochemical methods such as adsorptive stripping voltammetry (AdSV) [7-9] and catalytic voltammetry (CAdSV) [10-14] are among the most sensitive ones.

Complexes formed by Ge(IV) and organic compounds containing -OH groups in the ortho-position and exhibiting adsorptive properties, such as catechol [5,15-17], pyrogallol [5, 18, 19], pyrocatechol violet [20], alizarin red S [20], fluorone black [20], and quercetin [20], may be utilized for the sensitization of Ge(IV) determination by means of AdSV. Chloranilic acid (CAA) was also applied successfully for the abovementioned purpose [21,22].

However, the highest sensitivity and extremely low limit of detection of the voltammetric determination of several trace elements and compounds are attained via the simultaneous exploitation of adsorptive and catalytic effects [10-14]. In 
catalytic adsorptive stripping voltammetry (CAdSV), the final voltammetric response is the product of the dual amplification of the interfacial accumulation of a metal complex and a catalytic reaction. The mechanisms underlying catalytic reactions may differ and might be grouped into six categories [12-14]. Catalytic systems of the first and second kinds and catalytic systems involving hydrogen ions are the most frequently applied when describing the observed catalytic processes utilized for analytical purposes [10-14, 23].

CAdSV has successfully been used for the determination of germanium in the form of complexes of Ge(IV) with organic ligands, which are adsorbed on the surface of the working electrode, and induce the catalytic reduction of some oxidants, such as $\mathrm{BrO}_{3}{ }^{-}$[24, 25], $\mathrm{V}(\mathrm{IV})$ [26], V(IV).EDTA [27, 28], or V(IV)·HEDTA [29]. The described CAdSV systems applied for Ge(IV) determination may be considered to be of the first (e.g. [24]) or second kind [29]. In the case of the former, the reduced form of the depolarizer is immediately oxidized to its previous active form by an oxidizing agent in the vicinity of the electrode surface. For the latter, the reduced labile form of metal ion forms a very active complex with the oxidizing agent, which can immediately be reduced with the release of the reduced form of the depolarizer. A cyclic catalytic reaction is observed for both types of systems.

The aim of the present paper was to examine the electrochemical properties of a new catalytic adsorptive system in which the complex of Ge(IV), with the product of the reduction of chloranilic acid (CAA), adsorbed and reduced at the surface of the hanging mercury drop or renewable silver amalgam electrodes, and induces the catalytic reduction of the V(IV)·HEDTA complex. V(IV)·HEDTA complex was recently proposed as a very effective catalytic agent $[29,30]$ in the voltammetric quantification of $\mathrm{Ge}(\mathrm{IV})$ in a complex with catechol [29] and some other ligands [30], while CAA was selected as the ligand because its complexes have been very useful in the AdSV determination of several metals, such as Mo [31, 32], Sb [32-34], U [32, 34, 35], Sn [36], V [32, 37, 38], and Ge $[21,22]$, and the CAdSV determination of $\mathrm{W}$ [39]. To exploit the investigated system for analytical purposes, the conditions required to achieve very sensitive determination of Ge(IV) were also determined.

In addition to the hanging mercury drop electrode, the renewable cylindrical silver-based amalgam film electrode $(\mathrm{Hg}(\mathrm{Ag}) \mathrm{FE})[40,41]$ was also used in order to demonstrate its analytical utility in the CAdSV determination of germanium. The application of the renewable silver liquid amalgam film electrode is based on the cyclic renovation of the electrode surface, achieved by coating a silver wire with a fresh, liquid amalgam film $(1 \% \mathrm{w} / \mathrm{w})$ before each measurement. A small amount of the silver amalgam is sealed tightly inside the electrode corpus, which ensures that the electrode is safe to operate and offers good analytical performance.

\section{Experimental}

\section{Instrumentation}

The EAGRAPH (MTM Poland) electrochemical analyzer coupled with a controlled-growth mercury drop electrode (CGDME, Poland) used in the hanging mercury drop mode (HMDE) and the renewable silver amalgam film electrode $(\mathrm{Hg}(\mathrm{Ag}) \mathrm{FE})[40,41]$ were used to record voltammograms. The $\mathrm{Ag} / \mathrm{AgCl}(3 \mathrm{M} \mathrm{KCl})$ and platinum wire were used as the reference and auxiliary electrodes, respectively. The measuring $\mathrm{pH}$ of the solution was performed by means of multifunction meter CX-701 (Elmetron, Poland).

\section{Reagents}

All applied reagents were analytical grade and supplied by Merck (Germany). The stock solution with $0.2 \mathrm{M}$ of $\mathrm{VOSO}_{4}$ was prepared by dissolving $0.9094 \mathrm{~g}$ of $\mathrm{V}_{2} \mathrm{O}_{5}$ in a mixture containing $20 \mathrm{~mL}$ of water, $1 \mathrm{~mL}$ of $96 \% \mathrm{H}_{2} \mathrm{SO}_{4}$, and $2 \mathrm{~g}$ of oxalic acid using a water bath. After the complete dissolution of $\mathrm{V}_{2} \mathrm{O}_{5}$, the mixture was evaporated to white fumes of $\mathrm{H}_{2} \mathrm{SO}_{4}$ in order to decompose the excess of oxalic acid and, after cooling, transferred to a $50-\mathrm{mL}$ volumetric flask and filled to volume with water.

The standard solution of $0.01 \mathrm{M} \mathrm{Ge}(\mathrm{IV})$ was prepared by dissolving $0.1046 \mathrm{~g}$ of $\mathrm{GeO}_{2}$ in $80 \mathrm{~mL}$ of hot water and, after cooling, made up to $100 \mathrm{~mL}$ with water. Solution with lower concentrations of Ge(IV) was prepared by diluting the standard solution with $0.01 \mathrm{M} \mathrm{NaOH}$.

The solution of $0.005 \mathrm{M}$ chloranilic acid was prepared from the reagent purified previously by crystallization in water. The solutions of chloranilic acid were kept in the refrigerator and used within 2 weeks.

The catalytic reagent, namely the solution containing $0.04 \mathrm{M} \mathrm{V}(\mathrm{IV})$ and $0.08 \mathrm{M}$ HEDTA, was prepared by mixing $4 \mathrm{~mL} 0.2 \mathrm{M} \mathrm{VOSO}_{4}$ and $0.446 \mathrm{~g}$ of HEDTA in $8 \mathrm{~mL}$ of water, fixing $\mathrm{pH}$ to 2.0 by addition $20 \% \mathrm{NaOH}$ and transferring to a $10-\mathrm{mL}$ volumetric flask.

All solutions were prepared using deionized water (Millipore Simplicity UV). Oxygen was removed from the solutions by passing argon for $8 \mathrm{~min}$ before recording of voltammogram.

\section{Procedure}

Appropriate volumes of the $1 \mathrm{M} \mathrm{CH}_{3} \mathrm{COOH}, 0.005 \mathrm{M}$ chloranilic acid, and the solution containing $0.04 \mathrm{M} \mathrm{V(IV)}$ and $0.08 \mathrm{M}$ HEDTA were transferred to a voltammetric vessel and filled up to $10 \mathrm{~mL}$ with water. Quantitative voltammetric measurements were performed using the differential pulse mode (DPV) using standard addition procedure. All voltammograms were recorded in the cathodic direction from -0.4 to 
$-0.9 \mathrm{~V}$. Accumulation was performed by applying a potential of $-0.1 \mathrm{~V}$ for $60 \mathrm{~s}$ with stirring and, after a resting period of 15 $\mathrm{s}$, the voltammograms were recorded in differential pulse mode with polarization in the negative direction from -0.4 and down to $-0.9 \mathrm{~V}$. The other experimental parameters were as follows: step potential $2 \mathrm{mV}$, pulse potential $50 \mathrm{mV}$, and scan rate $50 \mathrm{mV} / \mathrm{s}$.

\section{Results}

\section{Catalytic system comprising Ge(IV), chloranilic acid, and V(IV).HEDTA complex}

Vanadium(IV) ions complexed by reagents from the aminopolycarboxylic acid family (i.e., HEDTA, EDTA, NTA) exhibit the ability to amplify the analytical signal of germanium bonded with ligands comprising a catechol moiety [28-32] (Scheme 1a) via a catalytic reaction. Recently, it was found that chloranilic acid (Scheme 1b), which is a member of the benzoquinone family of compounds, can be applied for germanium quantification by means of AdSV [21, 22].

The voltammograms recorded during the reduction of germanium(IV) in the presence of CAA (Scheme 1b) are shown in Fig. 1 (curves labeled a). A weak peak of germanium was observed at a potential of $-0.56 \mathrm{~V}$. However, after the addition of the V(IV).HEDTA complex to the analyzed solution, germanium signals were amplified considerably (Fig. 1, curves labeled $b$ ), by factors of 21 for the $\operatorname{HMDE}(\mathrm{A})$, and 18 for $\mathrm{Hg}(\mathrm{Ag}) \mathrm{FE}(\mathrm{B})$. Additionally, in the presence of $\mathrm{V}(\mathrm{IV})$. HEDTA, the germanium signals shifted towards potentials that are more negative by ca. $10-20 \mathrm{mV}$. The potential at which the $\mathrm{V}(\mathrm{IV}) \cdot \mathrm{HEDTA}$ complex undergoes reduction was - $1.07 \mathrm{~V}$, whereas CAA was reduced at $0.02 \mathrm{~V}$ (Fig. 2).

To gain deeper insight into the investigated electrochemical processes, CV voltammograms of Ge(IV) in the presence of CAA were also recorded-first in the absence of V(IV). HEDTA (Fig. 3a) and then in its presence (Fig. 3b). No peak of germanium was observed in the reverse scan in the absence of the vanadium complex (Fig. 3a-magnified view of the sections of voltammograms), which indicates that in the presence of CAA, the Ge(IV) was reduced irreversibly. In contrast, in the presence of $\mathrm{V}(\mathrm{IV}) \cdot \mathrm{HEDTA}$, the germanium signals were much higher and, in addition, both negative- and positive-going $\mathrm{CV}$ scans were cathodic, peak-shaped, and corresponded to reduction (Fig. 3b). The signal of Ge(IV) in the presence of CAA observed in the negative-going scan was non-symmetrical, with a maximum at $-0.56 \mathrm{~V}$ and a shoulder at $-0.62 \mathrm{~V}$, which was most likely a result of the total coverage of the electrode surface achieved in a solution with a high Ge(IV) concentration $(0.5$ $\mu \mathrm{M})$, which causes the electron transfer to occur across the adsorbed layer. The voltammetric signals recorded for the Ge(IV)·chloranilic acid-V(IV).HEDTA system in both DP and $\mathrm{CV}$ modes increased when the accumulation procedure was applied. The above-described findings clearly indicate that a new catalytic adsorptive stripping voltammetric system sensitive to germanium ions had been designed.

\section{Optimization}

\section{Chemical variables}

In order to elaborate a sensitive CAdSV procedure of germanium determination with the use of the designed (Ge(IV). a<smiles>Oc1ccccc1O</smiles>

b<smiles>O=C1C(O)=C(Cl)C(=O)C(O)=C1Cl</smiles>

C<smiles>Oc1c(O)c(Cl)c(O)c(O)c1Cl</smiles>

d<smiles>O=C1C(O)=C(Cl)C(=O)C(O)=C1Cl</smiles><smiles>Oc1c(O)c(Cl)c(O)c(O)c1Cl</smiles>

Scheme 1 The general structure of (a) catechol, (b) 2,5-dichloro-3,6-dihydroxy-1,4-benzoquinone, chloranilic acid (CAA), and (c) 2,5-dichloro1,3,4,6-tetrahydroxy-benzene (THDB). The scheme of CAA electroreduction (d). 
Fig. 1 DP AdSV curves recorded for a solution containing $25 \mathrm{nM}$ of $\mathrm{Ge}(\mathrm{IV})$ and chloranilic acid and in the absence (curves a) and presence of V(IV) HEDTA (curves b) using the HMDE (A) and $\mathrm{Hg}(\mathrm{Ag}) \mathrm{FE}(\mathrm{B})$. Supporting electrolyte: (A) $0.1 \mathrm{M}$ of acetic acid, $0.5 \mathrm{mM}$ of chloranilic acid, $1.5 \mathrm{mM}$ of V(IV), $3 \mathrm{mM}$ of HEDTA; (B) $0.075 \mathrm{M}$ of acetic acid, $0.77 \mathrm{mM}$ of chloranilic acid, $1 \mathrm{mM}$ of V(IV), $2 \mathrm{mM}$ of HEDTA. Instrumental parameters: $E_{\mathrm{acc}}=-0.1 \mathrm{~V}, t_{\mathrm{acc}}=60 \mathrm{~s}$.

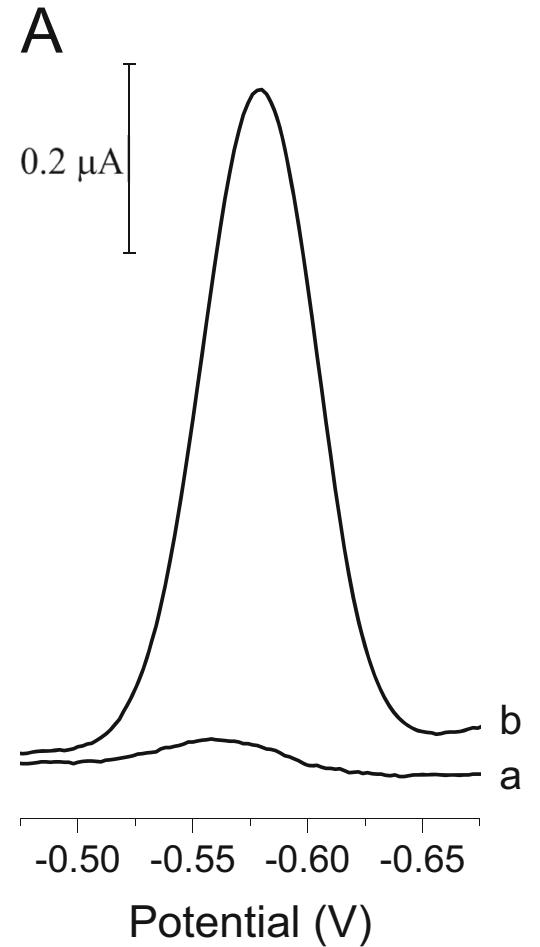

chloranilic acid-V(IV)·HEDTA) catalytic system, the influence of both chemical and instrumental factors on the measured germanium signal was evaluated. The chemical factors included the composition of the supporting electrolyte, namely the concentration of acetic acid and its $\mathrm{pH}$, as well as the concentrations of CAA and the V(V).HEDTA complex.

In preliminary studies, three supporting electrolytes with a pH of 2 were considered: $0.1 \mathrm{M} \mathrm{CH}_{3} \mathrm{COOH}[25$,

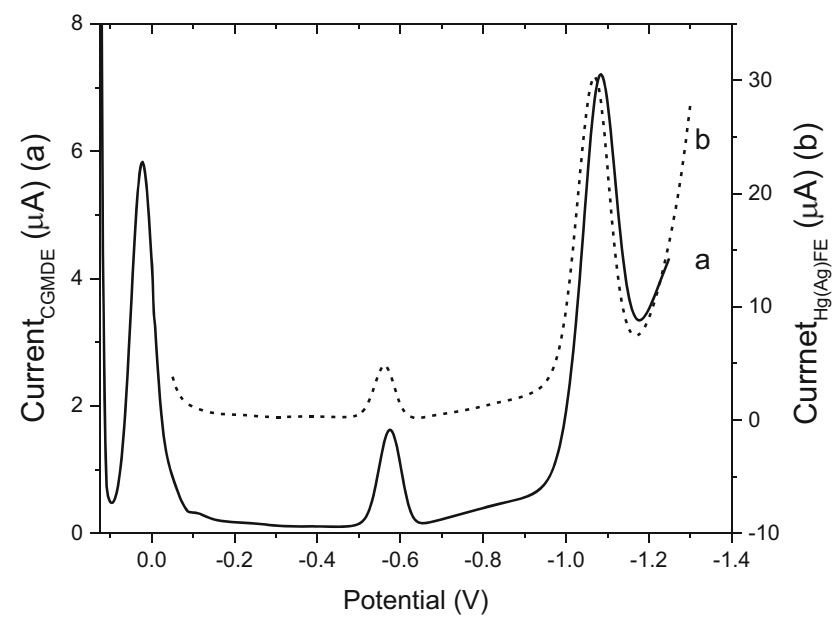

Fig. 2 DP AdSV curves recorded for a solution containing $50 \mathrm{nM}$ of $\mathrm{Ge}(\mathrm{IV})$ using the HMDE (a) and $\mathrm{Hg}(\mathrm{Ag}) \mathrm{FE}$ (b). Supporting electrolyte: $0.1 \mathrm{M}$ of acetic acid, $1.5 \mathrm{mM}$ of chloranilic acid, $2 \mathrm{mM}$ of V(IV), $4 \mathrm{mM}$ of HEDTA. Instrumental parameters: $E_{\mathrm{acc}}=-0.1 \mathrm{~V}, t_{\mathrm{acc}}=30 \mathrm{~s}$. In the case of the $\mathrm{Hg}(\mathrm{Ag}) \mathrm{FE}$, the initial potential of less than $0 \mathrm{~V}$ was applied to avoid oxidative damage to the electrode core.
26], $0.1 \mathrm{M} \mathrm{HCl}-\mathrm{KCl}$ buffer, and $0.1 \mathrm{M}$ betaine- $\mathrm{HCl}$ buffer. The geometry of the current-voltage curves recorded for $\mathrm{Ge}(\mathrm{IV})$ as well as its peak currents was found not to be significantly affected by the electrolyte type. Considering the shape of the peak, acetic acid was selected for further tests. The influence of the concentration of acetic acid on the germanium signal depended on the type of applied electrode. For instance, when HMDE was employed,

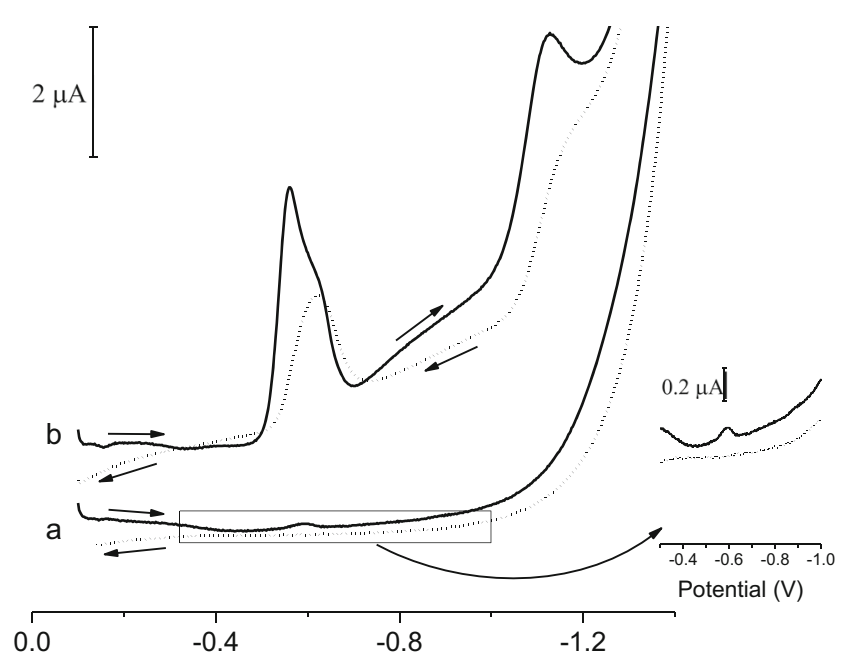

Fig. $3 \mathrm{CV}$ voltammograms recorded for a solution containing $0.5 \mu \mathrm{M}$ of $\mathrm{Ge}(\mathrm{IV})$ and chloranilic acid recorded in the absence (a) and presence of V(IV)-HEDTA (b). Composition of the solution: $0.1 \mathrm{M}$ of $\mathrm{CH}_{3} \mathrm{COOH}$, $1.5 \mathrm{mM}$ of chloranilic acid, $1.5 \mathrm{mM}$ of V(IV), $3 \mathrm{mM}$ of HEDTA. Solution $\mathrm{pH}=2$. Scan rate $=0.05 \mathrm{~V} \mathrm{~s}^{-1}$. Working electrode: HMDE 
Fig. 4 Catalytic adsorptive stripping voltammetric peak current recorded for $25 \mathrm{nM}$ of Ge(IV) depending on the concentration of acetic acid $(\mathbf{a}, \mathbf{c})$ and its $\mathrm{pH}(\mathbf{b}, \mathbf{d})$. Composition of the solution: $1.5 \mathrm{mM}$ of chloranilic acid, $1 \mathrm{mM}$ of V(IV), $2 \mathrm{mM}$ of HEDTA, $0.1 \mathrm{M}$ of acetic $\operatorname{acid}(\mathbf{b}, \mathbf{d})$ with a $\mathrm{pH}$ of $2(\mathbf{a}, \mathbf{c})$. Working electrode: HMDE $(\mathbf{a}, \mathbf{b})$ and $\mathrm{Hg}(\mathrm{Ag}) \mathrm{FE}(\mathbf{c}, \mathbf{d})$.

Instrumental parameters: $E_{\text {acc }}=-$ $0.1 \mathrm{~V}, t_{\mathrm{acc}}=60 \mathrm{~s}$

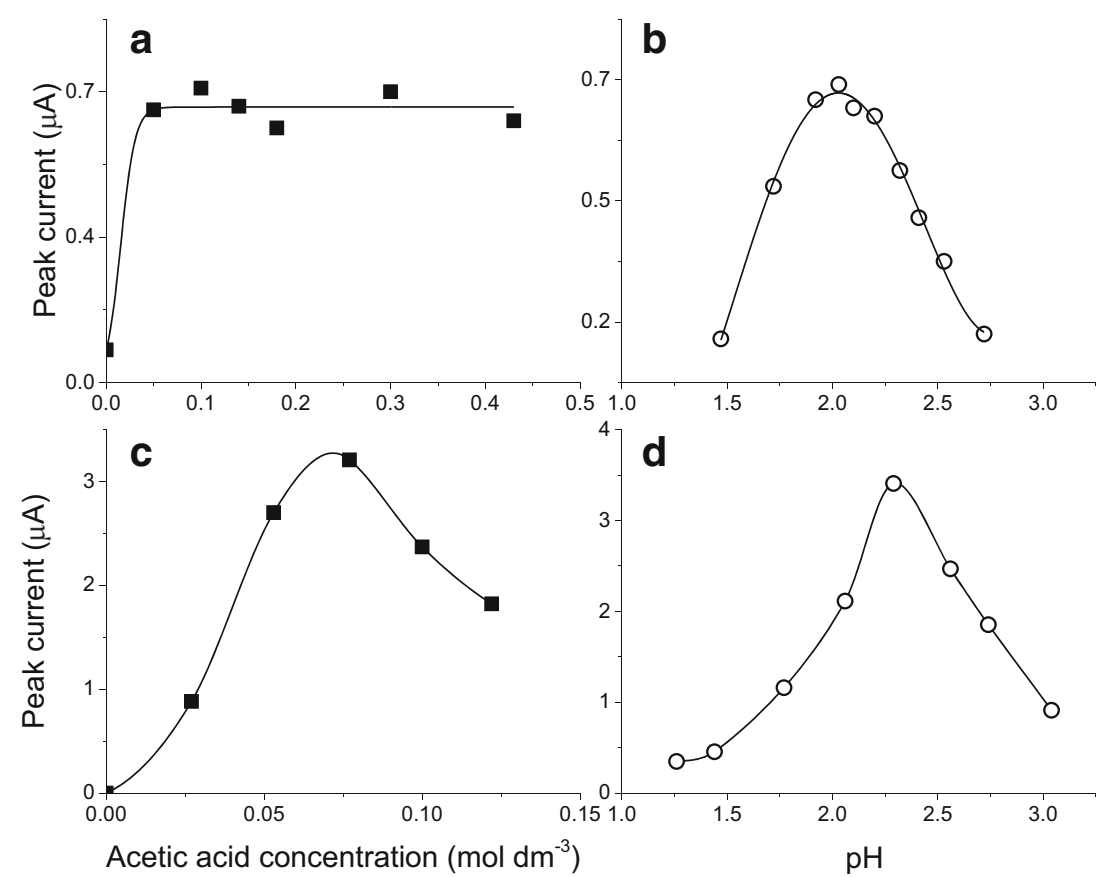

varying the concentration of $\mathrm{CH}_{3} \mathrm{COOH}$ in the range of 0.1-0.4 $\mathrm{M}$ did not have a significant influence on the catalytic peak current of Ge(IV) (Fig. 4a). In the case of $\mathrm{Hg}(\mathrm{Ag}) \mathrm{FE}$, peak current was strongly dependent on the supporting electrolyte concentration (Fig. 4c), and it reached a maximum for $0.075 \mathrm{M}$ of $\mathrm{CH}_{3} \mathrm{COOH}$. The $\mathrm{Ge}(\mathrm{IV})$ peak current was also strongly dependent on the $\mathrm{pH}$ of the supporting electrolyte regardless of the applied electrode (Fig. $4 \mathrm{~b}$ and d). Subsequent experiments were therefore performed either in $0.1 \mathrm{M}$ $\mathrm{CH}_{3} \mathrm{COOH}$ with a $\mathrm{pH}$ of 2 (when using the HMDE) or in $0.075 \mathrm{M} \mathrm{CH}_{3} \mathrm{COOH}$ with a $\mathrm{pH}$ of 2.3 (when $\mathrm{Hg}(\mathrm{Ag}) \mathrm{FE}$ was employed). The shape of Ge(IV) signals also varied to a considerable degree with the CAA
Fig. 5 Dependence of DP catalytic adsorptive stripping voltammetric peak current of Ge(IV) on the concentrations of chloranilic acid (a, c) and V(IV)-HEDTA (b, d). Examined solution: $25 \mathrm{nM}$ of Ge(IV), $1.5 \mathrm{mM}$ of chloranilic acid $(\mathbf{b}, \mathbf{d})$, $2 \mathrm{mM}$ of V(IV) (a, c), $4 \mathrm{mM}$ of HEDTA (a, c), $0.1 \mathrm{M}$ of acetic acid $(\mathrm{pH}=2)(\mathbf{a}, \mathbf{b})$ or $0.075 \mathrm{M}$ of acetic acid $(\mathrm{pH}=2.3)(\mathbf{c}, \mathbf{d})$. Instrumental parameters: $E_{\text {acc }}=-$ $0.1 \mathrm{~V}, t_{\mathrm{acc}}=30 \mathrm{~s}$.
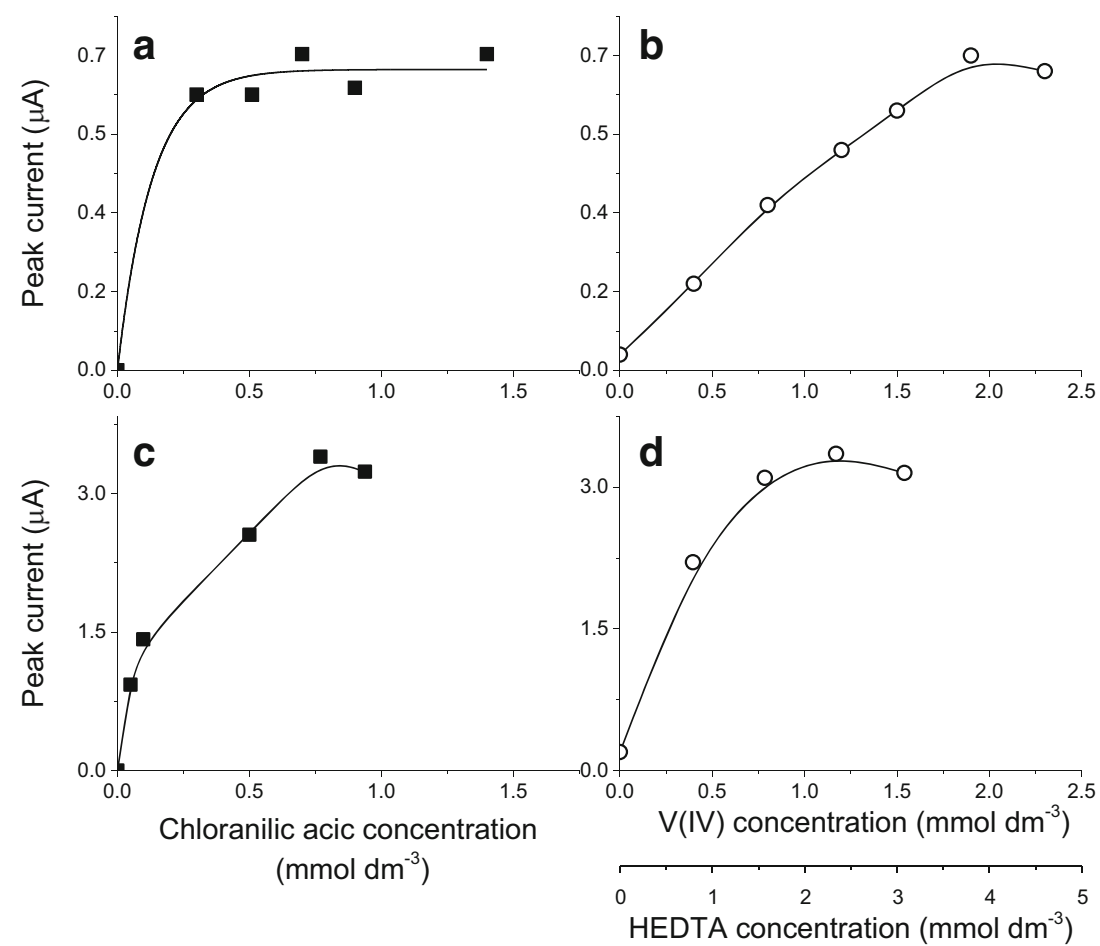

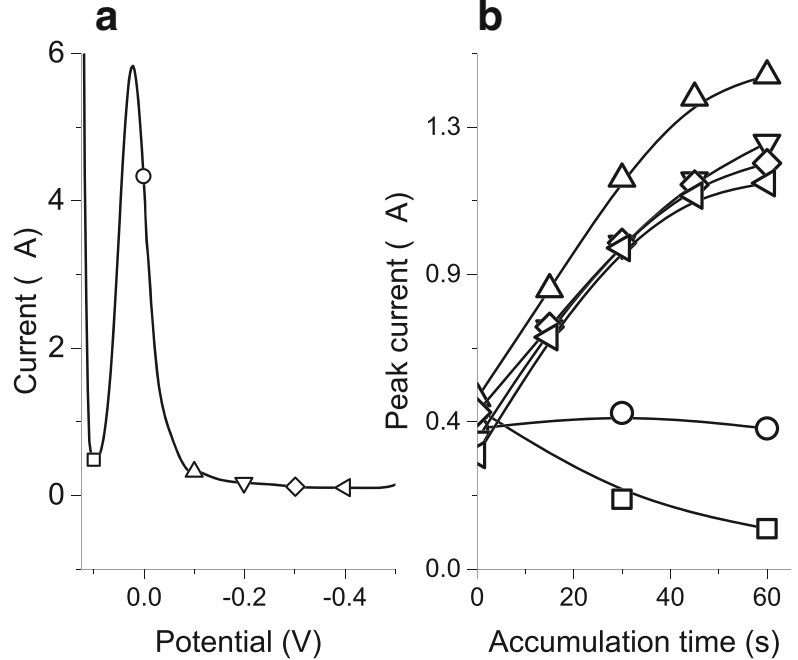

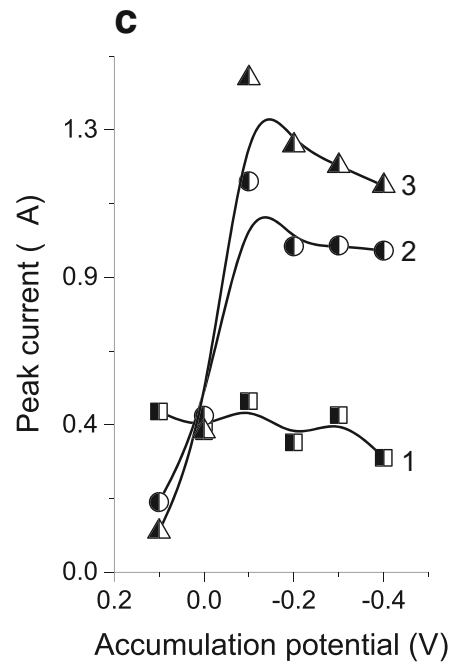

Fig. 6 (a) Magnified section of the voltammogram from Fig. 2, showing the peak corresponding to the reduction of chloranilic acid. The geometric shapes represent different accumulation potentials: $0.1 \mathrm{~V}, 0 \mathrm{~V},-0.1 \mathrm{~V},-$ $0.2 \mathrm{~V},-0.3 \mathrm{~V}$, and $-0.4 \mathrm{~V}$. (b) Dependence of DP catalytic adsorptive stripping voltammetric peak current of Ge(IV) on accumulation time for the selected accumulation potentials. (a) Dependence of DP catalytic peak current of Ge(IV) on accumulation potential after $0 \mathrm{~s}(1), 30 \mathrm{~s}(2)$, and $60 \mathrm{~s}$ (3) of accumulation. Composition of the solution: $50 \mathrm{nM}$ of Ge, $0.1 \mathrm{M}$ of $\mathrm{CH}_{3} \mathrm{COOH}, 0.5 \mathrm{mM}$ of chloranilic acid, $2 \mathrm{mM}$ of V(IV), $4 \mathrm{mM}$ of HEDTA. Working electrode: HMDE concentration (Fig. 5a, c). As this concentration increased, peak intensity increased. The current reached a maximum at $0.75 \mathrm{mM}$. Another important factor that affected the Ge(IV) signal was the concentration of the V(IV).HEDTA complex. Its influence on the Ge(IV) signal was examined by maintaining a 1:2 metal-to-ligand ratio for $\mathrm{V}(\mathrm{IV})$ ions and HEDTA, as recommended in a previous study [29]. The Ge(IV) peak currents obtained using the HMDE increased linearly at a rate of $19 \mu \mathrm{A}$ per $\mathrm{mM}$ of $\mathrm{V}(\mathrm{IV}) \cdot \mathrm{HEDTA}$ over the range from 0 to $2 \mathrm{mM}$ of $\mathrm{V}(\mathrm{IV}) \cdot \mathrm{HEDTA}$ and leveled off for higher concentrations (Fig. 5b). For $\mathrm{Hg}(\mathrm{Ag}) \mathrm{FE}$, a parabolic dependence of peak current on V(IV).HEDTA concentration was observed, with a maximum at $1.25 \mathrm{mM}$ (Fig. 5d).

\section{Instrumental variables}

The examined Ge(IV)-chloranilic acid-V(IV)-HEDTA system exhibited an interesting dependence of germanium peak current on accumulation potential and time. As shown in Fig. 6, this dependence varied for different accumulation potentials due to their relation to the reduction of CAA. When accumulation was performed at a potential of $0.1 \mathrm{~V}$-before the onset of CAA reduction proceeding according to Eq. (1) - the sensitivity of the Ge(IV) signal was low. When accumulation was performed at $0 \mathrm{~V}$, the peak recorded after $30 \mathrm{~s}$ of accumulation increased by $120 \%$. For the accumulation potential of $-0.1 \mathrm{~V}$, the germanium peak increased by a further $300 \%$. Increasing the accumulation time from 30 to $40 \mathrm{~s}$ and then to $60 \mathrm{~s}$ led to a modest increase in peak current, i.e., $20 \%$ and $5 \%$, respectively. The application of even more negative accumulation potentials was not beneficial to the peak current of germanium, since the germanium complex was either less active or its accumulation was less effective. The optimal accumulation time and potential selected for further investigations with the use of both HMDE and $\mathrm{Hg}(\mathrm{Ag}) \mathrm{FE}$ were therefore $60 \mathrm{~s}$ and $0.1 \mathrm{~V}$.

The strong dependence of the germanium peak current on accumulation potential and its relation to the reduction of chloranilic acid indicates that the product of the reduction of CAA (Scheme 1c) - namely the molecule containing two adjacent $-\mathrm{OH}$ groups (THDB), which is adsorbed at the surface of the electrode [42] — forms a complex with $\mathrm{Ge}(\mathrm{IV})$ in situ. THDB (Scheme 1c) contains two -OH groups in the ortho-position, as do ligands such as catechol, pyrogallol and gallic acid, which form strong and stable complexes with Ge(IV) [43]. This complex is then reduced to Ge(II)-THDB and participates in the catalytic process involving the Ge(II) THDB-V(IV). HEDTA system. The reduction of CAA over a similar potential range was also observed during the determination of uranium in the presence of CAA [44]. The authors of the papers describing the determination of other elements in the presence of CAA observed a dependence of accumulation potential that is similar to the one shown in Fig. 6 [22, 38]. On the other hand, Thomas and Henze mentioned that the formation of a complex of CAA with uranium ions takes place essentially at the electrode surface [42], which may support the above-suggested hypothesis. 
Based on the abovementioned assumption and results presented in a previous paper [29], the course of the catalytic process may proceed according to Eqs. (1)-(5).

$$
\begin{aligned}
& \mathrm{CAA}+2 \mathrm{H}^{+}+2 e^{-} \rightleftarrows \mathrm{THDB}_{\text {ads }} \\
& \mathrm{THDB}_{\text {ads }}+\mathrm{Ge}(\mathrm{IV}) \rightleftarrows(\mathrm{Ge}(\mathrm{IV}) \cdot \mathrm{THDB})_{\text {ads }}
\end{aligned}
$$

$$
(\mathrm{Ge}(\mathrm{IV}) \cdot \mathrm{THDB})_{\mathrm{ads}}+2 e \rightarrow(\mathrm{Ge}(\mathrm{II}) \cdot \mathrm{THDB})_{\mathrm{ads}}
$$

$(G e(I I) \cdot T H D B)_{a d s}+V(I V) \cdot H E D T A \rightarrow[G e(I I) \cdot T H D B-V(I V) \cdot H E D T A]_{a d s}$

$[G e(I I) \cdot T H D B-V(I V) \cdot H E D T A]_{a d s}+2 e \rightarrow(G e(I I) \cdot T H D B)_{a d s}+V(I I) \cdot H E D T A$

The Ge(IV)-THDB complex adsorbed at the surface of the electrode is electrochemically reduced to $\mathrm{Ge}(\mathrm{II})$. THDB (Eq. (3)) at the potential of $-0.56 \mathrm{~V}$. Process (3) is followed by the formation of an electroactive composite complex $[\mathrm{Ge}(\mathrm{II}) \cdot \mathrm{THDB}-\mathrm{V}(\mathrm{IV}) \cdot \mathrm{HEDTA}]_{\mathrm{ads}}$ (4), which contains $\mathrm{Ge}(\mathrm{II}) \cdot \mathrm{THDB}$, the product generated during the electroreduction of Ge(IV)-THDB as well as the V(IV) HEDTA present in the solution. In the composite complex, vanadium(IV) undergoes reduction, regenerating the $\mathrm{Ge}(\mathrm{II}) \cdot \mathrm{THDB}$ complex and a final electroinactive product, $\mathrm{V}(\mathrm{II}) \cdot \mathrm{HEDTA}$. The regenerated $\mathrm{Ge}(\mathrm{II}) \cdot \mathrm{THDB}$ attaches to the other V(IV).HEDTA molecule and the catalytic cycle described by Eqs. (4) and (5) repeats multiple times, contributing to the great amplification of the voltammetric response. The shape of both cathodic and anodic parts of the CV curves (Fig. $3 b)$ of the $\mathrm{Ge}(\mathrm{IV})-\mathrm{CAA}$ system in the presence of $\mathrm{V}(\mathrm{IV}) \cdot$ HEDTA is typical of catalytic systems of the second kind $[12,23]$.

\section{a}

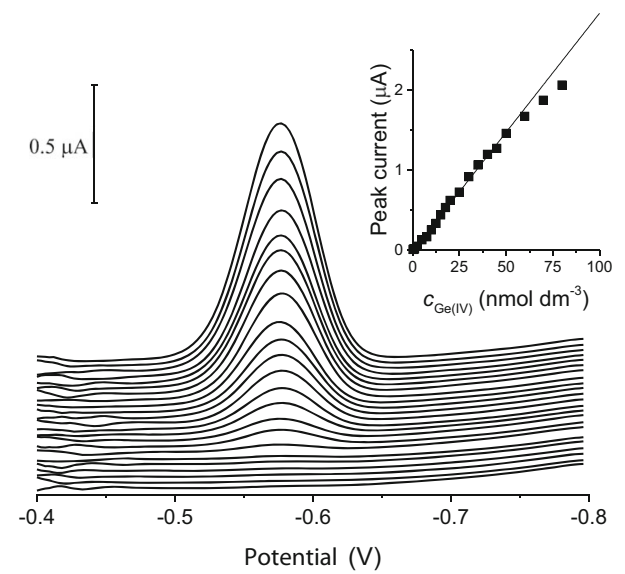

Fig. 7 DP catalytic adsorptive stripping voltammetric curves recorded for increasing $\mathrm{Ge}(\mathrm{VI})$ concentrations using the $\mathrm{HMDE}$ (a) and $\mathrm{Hg}(\mathrm{Ag}) \mathrm{FE}$ (b) and the corresponding calibration curves (shown as insets). Composition of the solution: (a) $0.1 \mathrm{M} \mathrm{CH}_{3} \mathrm{COOH}, 0.75 \mathrm{mM}$ chloranilic acid, $2 \mathrm{mM}$

\section{Interferences}

The influence of other elements on the determination of Ge(IV) was tested in the supporting electrolyte containing $0.1 \mathrm{M}$ of acetic acid ( $\mathrm{pH}$ 2), $0.75 \mathrm{mM}$ of chloranilic acid, $2 \mathrm{mM}$ of V(IV), $4 \mathrm{mM}$ of HEDTA, and $25 \mathrm{nM}$ of Ge(IV). The voltammograms were recorded in DP mode after $60 \mathrm{~s}$ of accumulation at $-0.1 \mathrm{~V}$. It was found that a 10 -fold excess of $\mathrm{Pb}, \mathrm{Sb}, \mathrm{As}, \mathrm{Cu}$, $\mathrm{Mo}, \mathrm{Te}$, or I ions did not affect the Ge(IV) signal. When present in increasingly higher amounts, the abovementioned elements gradually reduced the Ge(IV) signal. The addition of Se and $\mathrm{Bi}$ at concentrations equal to that of Ge(IV) led to a $30 \%$ reduction in the germanium peak current. Cadmium ions, on the other hand, substantially suppressed the germanium signal when present at a concentration equal to half of the germanium concentration; for a 1:1 Ge(IV):Cd(II) concentration ratio, a nearly complete loss of the germanium signal was observed.

The germanium signal was found to be sensitive to surfaceactive substances, as revealed via tests involving Triton $\mathrm{X}-100$. In a solution containing $1 \mathrm{mg} \mathrm{L^{-1 }}$ of Triton X-100, the germanium signal dropped by $70 \%$, and for $2 \mathrm{mg} \mathrm{L}^{-1}$ of Triton X-100, it retained only $3 \%$ of its initial value.

\section{Analytical performance}

The analytical performance of Ge(IV) in the presence of chloranilic acid and the V(IV)·HEDTA system was assessed in experiments carried out under the following conditions: HMDE $-0.1 \mathrm{M}$ of $\mathrm{CH}_{3} \mathrm{COOH}$ with a $\mathrm{pH}$ of $2,0.75 \mathrm{mM}$ of chloranilic acid, $2 \mathrm{mM}$ of $\mathrm{V}(\mathrm{IV}) \cdot \mathrm{HEDTA}$; $\mathrm{Hg}(\mathrm{Ag}) \mathrm{FE}-$ $0.075 \mathrm{M}$ of $\mathrm{CH}_{3} \mathrm{COOH}$ with a $\mathrm{pH}$ of $2.3,0.75 \mathrm{mM}$ of chloranilic acid, $1.25 \mathrm{mM}$ of V(IV)·HEDTA. Accumulation was performed at $-0.1 \mathrm{~V}$ for $60 \mathrm{~s}$. CAdSV curves were recorded for solutions

b

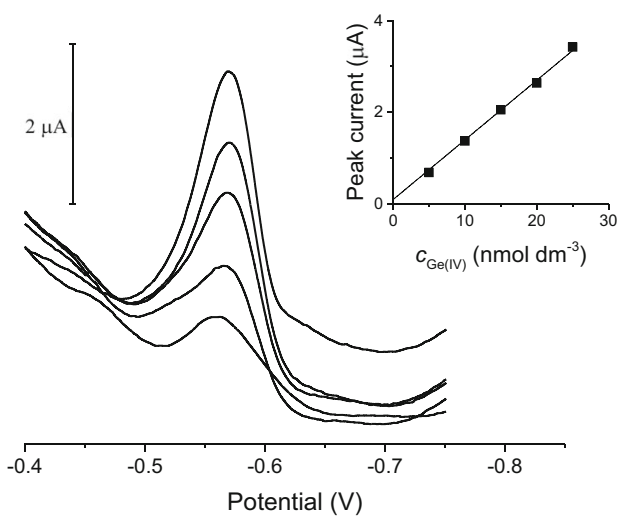

V(IV), 4 mM HEDTA, pH 2.0; (b) $0.075 \mathrm{M} \mathrm{CH}_{3} \mathrm{COOH}, 0.75 \mathrm{mM}$ chloranilic acid, $1.25 \mathrm{mM}$ V(IV), $2.5 \mathrm{mM}$ HEDTA, pH 2.3. $E_{\mathrm{acc}}=-$ $0.1 \mathrm{~V}, t_{\mathrm{acc}}=60 \mathrm{~s}$ 
containing $0.75-80 \mathrm{nM}$ of Ge(IV) when HMDE was used and 1$25 \mathrm{nM}$ of Ge(IV) for $\mathrm{Hg}(\mathrm{Ag})$ FE. They are shown in Fig. 7. They were well-developed over the entire investigated Ge(IV) concentration range; the signal increased linearly with Ge(IV) concentration in the range from 0.75 to $50 \mathrm{nM}\left(I_{\mathrm{p} \mathrm{HMDE}}=(0.0299 \pm\right.$ $\left.0.0004) c-(0.015 \pm 0.009) ; r^{2}=0.9970\right)$ and from 1 to $25 \mathrm{nM}$ $\left(I_{\mathrm{p} \mathrm{Hg}(\mathrm{Ag}) \mathrm{FE}}=(0.130 \pm 0.003) c-(0.010 \pm 0.05) ; r^{2}=0.9974\right)$, where peak current is expressed in $\mu \mathrm{A}$ and $\mathrm{Ge}(\mathrm{IV})$ concentration is in $\mathrm{nM}$. In the case of HMDE electrode, the repeatability for 1 $\mathrm{nM}$ of $\mathrm{Ge}(\mathrm{IV})$ and 10 measurements was equal to $5.3 \%$ and the LOD was found to be $0.085 \mathrm{nM}$, whereas for $\mathrm{Hg}(\mathrm{Ag}) \mathrm{FE}$, the repeatability for $5 \mathrm{nM}$ of Ge(IV) and 10 measurements was equal to $5.8 \%$ and the LOD had a value of $0.70 \mathrm{nM}$.

The elaborated procedure was tested using real samples containing germanium (mineral water no. 1) or spiked with germanium standard (mineral water no. 2 and tap water). Both mineral waters were collected and manufactured in Poland, carbonated, and sold in glass bottles. Mineral water no. 1 was highly mineralized (5225 $\mathrm{mg} \mathrm{L}^{-1}$ of total dissolved solids (TDS)). It contained $17.69 \mathrm{mg} \mathrm{L}^{-1}$ of germanium, as reported by authors who applied total reflection X-ray fluorescence (TXRF) [47] to examine it. The mineral water no. 2 was low mineralized ( $475 \mathrm{mg} \mathrm{L}^{-1} \mathrm{TDS}$ ). It did not show the presence of a detectable amount of germanium, similarly to tap water collected in our laboratory. The concentration of Ge(IV) measured in the mineral water sample no. 1 by means of the developed CAdSV procedure was $18.6 \pm 1.1 \mu \mathrm{g}$ $\mathrm{L}^{-1}$, and this value is consistent with the value of $17.69 \mu \mathrm{g} \mathrm{L} \mathrm{L}^{-1}$ reported earlier [47]. The two remaining samples were spiked with $5 \mathrm{nM}$ of $\mathrm{Ge}(\mathrm{IV})$, which resulted in recoveries of $98.9 \pm$ $1.0 \%$ for mineral water 2 and $102 \pm 12 \%$ for tap water.

\section{Conclusions}

The addition of V(IV)·HEDTA to a solution containing acetic acid and CAA significantly increased the adsorptive stripping voltammetric signal of germanium via a catalytic reaction occurring in the presence of the vanadium complex. The dependence of the germanium response on accumulation potential and time implies that Ge(IV) may form a complex with the product of the reduction of CAA; this complex has a strong tendency to adsorb at the electrode surface and to induce the catalytic process.

The careful optimization of chemical and instrumental variables, especially the accumulation potential, allowed a very sensitive procedure for the determination of germanium to be designed. Depending on the applied electrode, the germanium signals were $11.75(\mathrm{Hg}(\mathrm{Ag}) \mathrm{FE})$ or 20.7 (HMDE) times higher than those recorded in the absence of V(IV)-HEDTA. It should be emphasized that the replacement of the HMDE with an environmentally safer alternative, namely the $\mathrm{Hg}(\mathrm{Ag}) \mathrm{FE}$, did not compromise the high sensitivity of analytical signals, as both electrodes can be used to record signals that are linearly dependent on the Ge(IV) concentration within a similar concentration range $(0.75 \mathrm{nM}$ to $50 \mathrm{nM}$ for the HMDE and $1 \mathrm{nM}$ to $25 \mathrm{nM}$ for the $\mathrm{Hg}(\mathrm{Ag}) \mathrm{FE})$. Both tested electrodes - the HMDE and the renewable $\mathrm{Hg}(\mathrm{Ag}) \mathrm{FE}$ - may be used to determine ultratrace levels of Ge(IV) with high sensitivity and low limits of detection $(0.085 \mathrm{nM}$ for the HMDE and $0.70 \mathrm{nM}$ for the $\mathrm{Hg}(\mathrm{Ag}) \mathrm{FE}$ ) for an accumulation time of $60 \mathrm{~s}$. The application of the $\mathrm{Hg}(\mathrm{Ag}) \mathrm{FE}$, however, allows researchers to significantly limit the issues stemming from the application of mercury at laboratories. The elaborated procedure was tested using real and spiked samples, and it was determined that the proposed method can be applied for the determination of Ge(IV) in water samples.

Funding information Financial support from the Polish National Science Centre (Project 2014/15/B/ST8/03921) and the Erasmus mobility grant (V. Manolopoulou) is gratefully acknowledged.

Open Access This article is licensed under a Creative Commons Attribution 4.0 International License, which permits use, sharing, adaptation, distribution and reproduction in any medium or format, as long as you give appropriate credit to the original author(s) and the source, provide a link to the Creative Commons licence, and indicate if changes were made. The images or other third party material in this article are included in the article's Creative Commons licence, unless indicated otherwise in a credit line to the material. If material is not included in the article's Creative Commons licence and your intended use is not permitted by statutory regulation or exceeds the permitted use, you will need to obtain permission directly from the copyright holder. To view a copy of this licence, visit http://creativecommons.org/licenses/by/4.0/.

\section{References}

1. Schauss AG (1991) Nephrotoxicity in humans by the ultratrace element germanium. Ren Fail 13:1-4

2. Tao SH, Bolger PM (1997) Hazard assessment of germanium supplements. Regul Toxicol Pharmacol 25:211-219

3. Schauss AG (1991) Nephrotoxicity and neurotoxicity in humans from organogermanium compounds and germanium dioxide. Biol Trace Elem Res 29:267-280

4. Henze G (1986) 100 Jahre Germanium - Die Entwicklung der Analytik. Fresenius Z Anal Chem 324:105-110

5. Schleich C, Henze G (1990) Trace analysis of germanium. Part 2. Polarographic behaviour and determination by adsorptive stripping voltammetry. Fresenius J Anal Chem 338:145-148

6. Keith LS, Faroon OM, Maples-Reynolds N, Fowler BA (2015) Germanium. In Handbook on the toxicology of metals, fourth edition, Elsevier

7. Paneli MG, Voulgaropoulos A (1993) Applications of adsorptive stripping voltammetry in the determination of trace and ultratrace metals. Electroanalysis 5:355-373

8. Kalvoda R (1994) Review of adsorptive stripping voltammetry assessment and prospects. Fresenius J Anal Chem 349:565-570

9. Economou A, Fielden PR (1997) Applications, potentialities and limitations of adsorptive stripping analysis on mercury film electrodes. TrAC Trends Anal Chem 16:286-292

10. Czae M, Wang J (1999) Pushing the detectability of voltammetry: how low can we go? Talanta 50:921-928

11. Banica FG, Ion A (2000) In: Meyers RA (ed) Electrocatalysisbased kinetics determination, in Encyclopedia of Analytical Chemistry: Instrumentation and Applications. John Wiley \& Sons, New York

12. Bobrowski A, Zarębski J (2000) Catalytic systems in adsorptive stripping voltammetry. Electroanalysis 12:1177-1186 
13. Bobrowski A, Zaręskki J (2001) Application of catalytic adsorptive stripping voltammetry in water analysis. Water Sci Tech-W Sup 1:1-8

14. Bobrowski A, Zarębski J (2008) Catalytic adsorptive stripping voltammetry at film electrodes. Curr Anal Chem 4:191-201

15. Ly SY, Song SS, Kim SK, Jung YS, Lee CH (2006) Determination of Ge(IV) in rice in a mercury-coated glassy carbon electrode in the presence of catechol. Food Chem 95:337-343

16. Muniz Alvarez JL, Garcia Calzon JA, Lopez Fonseca JM (1999) Electrochemical Reduction of Ge(IV) Catalyzed by o-Catechol at the Dropping Mercury Electrode and at the Hanging Mercury Drop Electrode after Adsorptive Preconcentration. Electroanalysis 11:656-659

17. Muniz Alvarez JL, Garcia Calzon JA, Lopez Fonseca JM (2001) Square-wave voltammetry of the o-catechol-Ge(IV) catalytic system after adsorptive preconcentration at a hanging mercury drop electrode. Talanta 53:721-731

18. Sun C-Q, Gao Q, Liu L (1995) Adsorptive stripping measurement of germanium(IV) in the presence of pyrogallol. Talanta 42:881884

19. Aguilar JC, de Gyves J (1995) Determination of germanium(IV) in sulphide ores by differential pulse polarography in pyrogallolsulfuric acid media. Anal Chim Acta 306:243-247

20. Bond AM, Kratsis S, Newman OMG (1998) Adsorptive Stripping voltammetric determination of germanium in zinc plant electrolyte. Electroanalysis 10:387-392

21. Grabarczyk M (2017) Optimization of adsorptive stripping voltammetry procedure using chloranilic acid as a complexing agent for the determination of ultra-trace germanium in natural water samples. J Electrochem Soc 164:H872-H876

22. Grabarczyk M, Adamczyk M (2018) Bismuth film electrode and chloranilic acid as a new alternative for simple, fast and sensitive Ge(IV) quantification by adsorptive stripping voltammetry. RSC Adv 8:15215-11522

23. Mirčeski V, Bobrowski A, Zarębski J, Spasovski F (2010) Electrocatalysis of the first and second kind: theoretical and experimental study in conditions of square-wave voltammetry. Electrochim Acta 55:8696-8703

24. Shi J, Jiao K (1995) Adsorptive complex catalytic polarographic determination of germanium in soils and vegetables. Anal Chim Acta 309:103-109

25. Zhong S, Su J, Chen L, Tong J, Jia W, Li X, Zou H (2013) Determination of total germanium in Chinese herbal remedies by square-wave catalytic adsorptive cathodic stripping voltammetry at an improved bismuth film electrode. Int J Electrochem Sci 735019

26. Muniz Alvarez JL, Garcia Calzon JA, Lopez Fonseca JM (2001) Coupling of ligand-catalyzed electroreduction of metal ions with redox electrocatalysis. Application of the o-Catechol-Ge(IV)V(IV) double catalytic system for the sensitive determination of o-Catechol. Electroanalysis 13:181-185

27. Li Y-H, Chen X-H, Huang M-H, Zhou F-Q (2007) Catalytic adsorptive stripping voltammetry of germanium(IV) in the presence of gallic acid and vanadium(IV)-EDTA. Electroanalysis 19:704-708

28. Sun C, Gao Q, Xi J, Xu H (1995) Determination of germanium(IV) by catalytic cathodic stripping voltammetry. Anal Chim Acta 309: 89-93

29. Zarębski J, Bobrowski A, Gonciarczyk J, Królicka A (2019) Extremely sensitive germanium stripping voltammetric determination with the use of a new Ge(IV)-catechol -V(IV)-HEDTA catalytic adsorptive system. Electrochim Acta 324:134859

30. Zarębski J, Bobrowski A, Gonciarczyk J, Królicka A (2020) Selection of optimal ligand and vanadium(IV) complexonate oxidant for sensitive catalytic adsorptive stripping voltammetric quantification of germanium, Electroanalysis under review

31. Karakaplan M, G. Henze (1993) Application of adsorptive stripping voltammetry to trace measurements of molybdenum in plant materials. Electroanalysis 5:623-625

32. Sander S (1999) Simultaneous adsorptive stripping voltammetric determination of molybdenum(VI), uranium(VI), vanadium(V), and antimony(III). Anal Chim Acta 394:81-89

33. Belzile N, Chen W (1999) Analytical procedure for determination of antimony(III) and total antimony in amorphous iron and manganese oxyhydroxide. Can J Anal Sci Spectrosc 44:85-88

34. Sander S, Henze G (1994) Adsorption voltammetric techniques for the determination of uranium(VI) with 2,5-dichloro-3,6-dihydroxy1,4-benzoquinone as complex forming reagent. Fresenius J Anal Chem 349:654-658

35. Sander S, Wagner W, Henze G (1995) Direct determination of uranium traces by adsorptive stripping voltammetry. Anal Chim Acta 305:154-158

36. Heppeler F, Sander S, Henze G (1996) Determination of tin traces in water samples by adsorptive stripping voltammetry. Anal Chim Acta 319:19-24

37. Sander S, Henze G (1996) Adsorptive stripping voltammetric determination of vanadium as chloranilic complex. Fresenius J Anal Chem 356:259-262

38. Piech R, Baś B, Paczosa-Bator B, Kubiak WW (2009) Adsorptive stripping voltammetric determination of vanadium $(\mathrm{V})$ with chloranilic acid using cyclic renewable mercury film silver based electrode. J Electroanal Chem 633:333-338

39. Zarębski J, Henze G (1997) Analytical aspects of voltammetric and photometric investigations of tungsten(VI)-chloranilic acid complex. Chem Anal 42:15-21

40. Baś B, Kowalski Z (2002) Preparation of silver surface for mercury film electrode of prolonged analytical application. Electroanalysis 14:1067-1071

41. Bobrowski A, Królicka A, Bobrowski R (2016) Renewable silver amalgam film electrodes in electrochemical stripping analysis - a review. J Solid State Electrochem 20:3217-3228

42. Thomas FG, Henze G (2001) Introduction to voltammetric analysis. CSIRO, Collingwood

43. Pokrovski GS, Martin F, Hazemann J-L, Schott J (2000) An X-ray absorption fine structure spectroscopy study of germanium-organic ligand complexes in aqueous solution. Chem Geol 163:151-165

44. Satpati AK, Sahoo S, Ravindran PV, Venkateswaran G (2010) Stripping voltammetric determination of uranium traces in sea water samples: effect of surfactants on the measurements. Anal Lett 43:644-657

Publisher's note Springer Nature remains neutral with regard to jurisdictional claims in published maps and institutional affiliations. 